\title{
The Inheritance and Development of Rammed Earth Wall in the construction of New Countryside
}

\author{
Liu wei $^{1 . a, *, \text { Du chenchen }}{ }^{2 . b}$ \\ ${ }^{1}$ Shenyang Aerospace University, Shenyang 110136, China \\ 2 Shenyang Aerospace University, Shenyang 110136, China \\ a*1424817759@qq.com, ${ }^{b} 707596544 @ q q . c o m$
}

Keywords: inheritance and development; rammed earth wall; construction; New Countryside

Abstract: The 19th report put forward the construction of prosperous, strong, democratic, civilized, harmonious and beautiful modern socialist country, to focus on building new and beautiful China and practice the concept of green. In 2017, in the Central No.1 document, a clear proposal to further develop rural residential environment and the construction of beautiful and livable countryside is proposed. Rammed earth wall also has a long history in the study of historical materials. In many villages in China, rammed earth walls are also widely used in corners of the countryside as a building or decoration material. Based on the ecological civilization theory and practice research, this paper discusses the culture, innovation, inheritance, development and artistic value in terms of analysis of rammed earth wall in the status quo and problems in the new rural construction, and discusses how to make the rammed earth wall get better inheritance and development in the new rural construction.

\section{The Current Situation of Rammed Earth Wall in the Construction of New Countryside}

Soil is a very common building material in the countryside, so rammed earth wall building is widely distributed in China. In twelve provinces in China's central and western regions, the average proportion of rural houses with rammed earth walls as the main structural materials is more than 20\%. In Gansu, Yunnan and Tibet in China, the proportion of rural houses which using rammed earth walls as the main structural materials is more than $60 \%{ }^{[1]}$.

Rammed earth is one of the oldest building materials in China. As early as more than 4000 years ago, the ancient working people in China had mastered the mature rammed earth technology. The development of rammed earth technology can be described by "dynastic changes" in the past dynasties, which culminated in the development of rammed earth technology in the period of the spring and autumn period. At present, China's existing and still used rammed earth wall residential buildings are mainly concentrated in the loess plateau region, south China region, southwest region, Qinghai plateau region and Xinjiang region. With the development of construct skill, the old rammed earth wall technology has gradually dropped out of the historical stage, and when it comes to "rammed earth", it will be associated with poverty. However, with the construction and development of the city, the ecological environment deteriorates year by year, and the ecological 
architecture becomes the development trend, and then the building of rammed earth as building materials is widely mentioned. In recent decades, began extensive and in-depth study of rammed earth technology abroad, especially as the United States, Germany, Australia, France and other countries research results, rammed earth wall building design, construction and so on a series of problems of its standardization process. But for China, as early as in ancient times was used in the fruits of the rammed earth wall, the fort, walls, etc., for the existing in some ancient city wall and military sites still can see this kind of rammed earth wall production technology, and Fujian province is the Chinese traditional rammed earth wall construction technology to the peak ${ }^{[2]}$.

Study of rammed earth buildings in China started late, and accelerated the pace of socialist modernization construction in rural areas, and at the same time, a lack of system knowledge study and the modern technology application, makes some rammed earth wall construction has not been able to be very well in the rural construction, some are being destroyed and some incomplete already has a large area and collapsed. But as people thought culture level rise and the country to the adjustment of rural policies, to build ecological civilization, beautiful livable new rural areas, makes some people keep up with the pace of The Times, studied the rammed earth material analysis and experiment, the seismic performance, thermal performance is relatively good. Among them, some local designers and experts have designed and repaired the rammed earth vernacular architecture in the new countryside, which has attracted wide attention at home and abroad ${ }^{[3]}$.

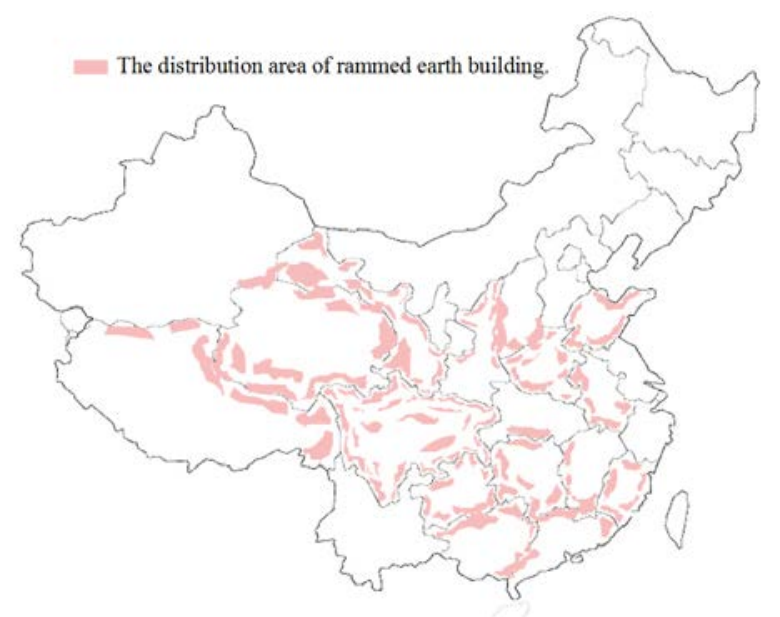

Fig.1 The area of rammed earth in China (incomplete statistics).

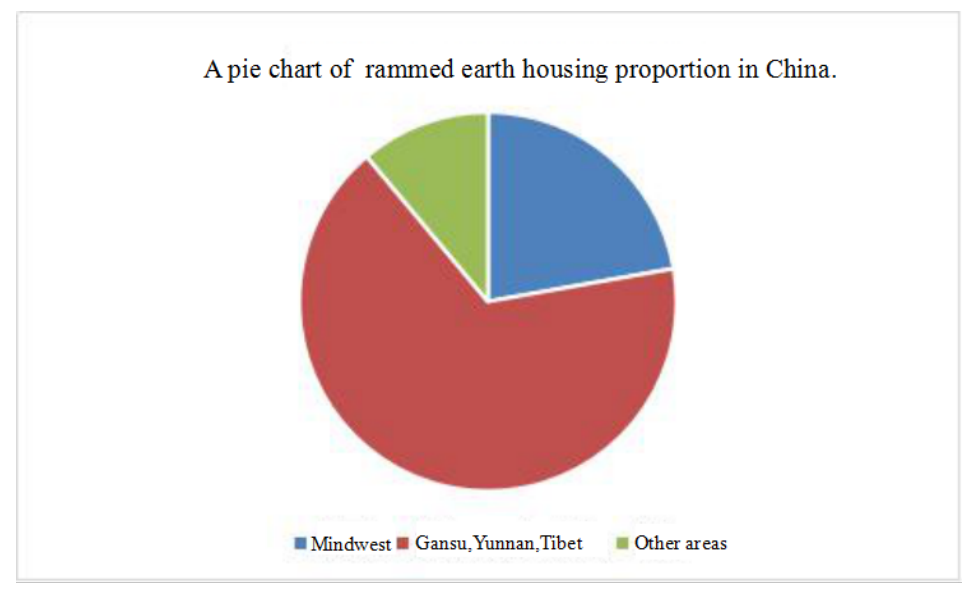

Fig. 2. Pie chart of rammed earth housing in China. 


\section{The Dilemma of Current Rammed Earth Wall in the New Countryside Construction}

\subsection{Material matching problem}

Properties vary in different parts of the land, the workers always in front of the rammed earth building optional dig up the soil in the construction site, and not to recognize the quality and characteristics of soil, so a lot of substandard is used in the soil.

Because rural craftsmen untrained professional construction training, at the same time, lack of professional knowledge of building construction, with only experience to guide the construction, the lack of certain scientific and professional, as a result, rammed earth building there are a lot of problems, safety performance is not high. Traditional rammed earth buildings using artificial wall, the wall of compactness mainly rely on the workers themselves to control, different workers struck rammed earth strength is different, which is a big difference in the soil compaction effect. At the same time, soil moisture content control is not strict, the survey found that rural built for the convenience of ram, choose the moisture content of soil is generally high, dry rammed earth, not only easy to crack, strength is generally low. Therefore, rammed earth was used as the main building materials need to have a definite strength, and the need to reach a certain compactness, just as a reinforced concrete structure, need certain reasonable matching combination of stone, gravel and sand. Through the principle of Apollo accumulation, the different particle combinations in the rammed earth can effectively reduce the gap between particles. However, in rammed earth materials, these Spaces are usually water and air, and their presence can weaken the strength of rammed earth walls and cause cracks ${ }^{[4]}$.

In addition, the wall in the outer wall construction order confusion, no cross wall, the results will make rammed earth wall in up and down seam, destroy the wall of the neat, plus based approach is not reasonable, construction speed and so on a series of problems, will reduce the building structure security, reliability, greatly hindered the rammed earth construction quality. Existing in the rural areas of rammed earth wall construction ratio has obvious problems in the construction, due to the construction of rammed earth wall when the compaction degree and density ratio, high quality and strength is not enough, the foundation is not solid, construction technology does not reach the designated position, moisture content control does not reach the designated position and the mixing uniformity is not high, leading to such as daylighting, ventilated problems, some in the rainy season, rammed earth wall after the heavy rain wash easy to collapse and collapse. With the increase of the number of years, the traditional rammed earth wall is easy to weathering, aging and falling off ${ }^{[5]}$.

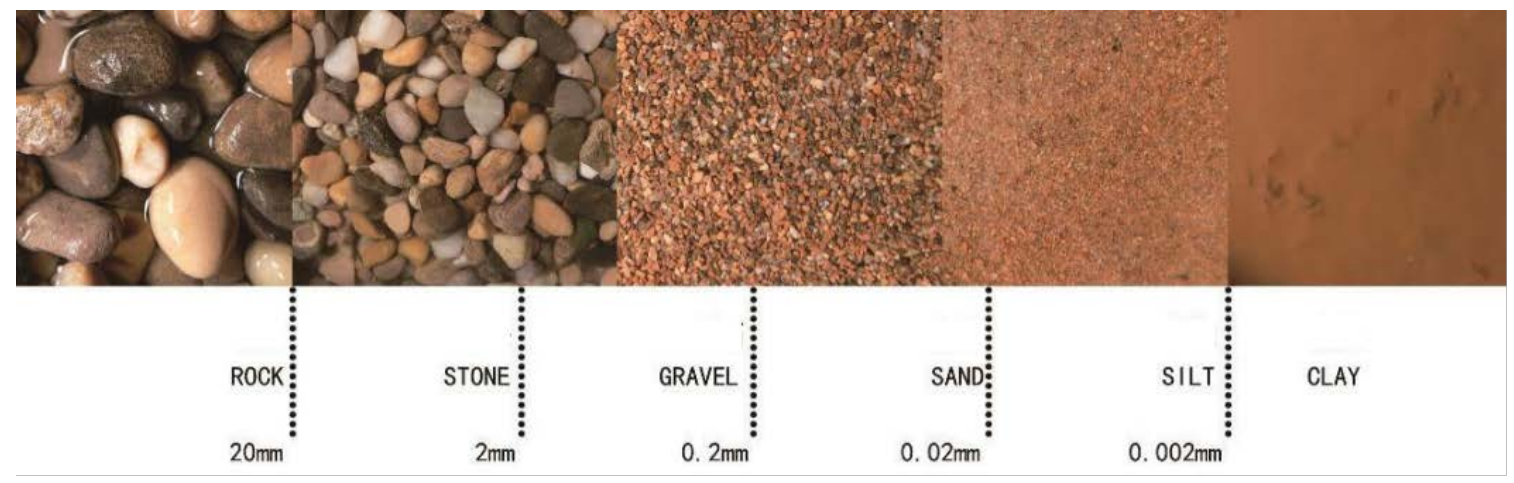

Fig. 3 generalized soil

(image source: "new type rammed earth green residential building guide manual”) 


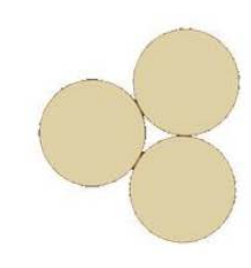

Stone

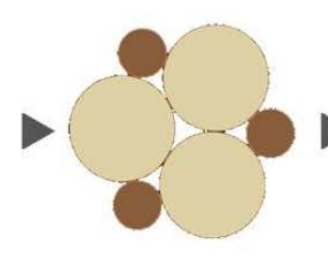

Stone + Gravel

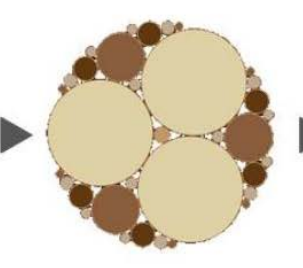

Stone+Gravel+Fine sand

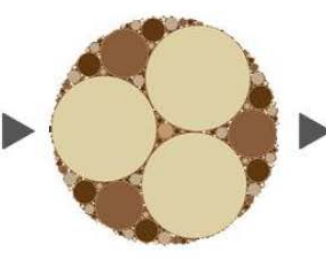

Stone + Gravel+Fine sand + Powder

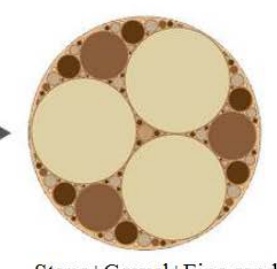

tone + Gravel + Fine san + Powder+Comisd

Fig. 4 The schematic diagram of the Apollo accumulation principle

(image source: "new type rammed earth green residential building guide manual”)

\subsection{The structural mechanics}

Because rammed earth wall is not strong in the construction process, it is easy to crack at the same time and the mechanical property of the enclosure structure is poor. Rammed earth density of $1800 \sim 2000 \mathrm{~kg} / \mathrm{m}$ after, the compressive strength of $2.4 \mathrm{Mpa}$, can be used as a bearing or from the structure of the load-bearing wall materials, but because of the particularity of raw soil material, makes the rammed earth construction in many countries are not the corresponding building codes, so in the application of contemporary architecture, rammed earth wall used as the retaining wall structure ${ }^{[6]}$.

Considering the stability of the wall, when the independent wall of rammed earth wall as a space than its height should not be greater than 10:1, but such as rammed earth wall and other artifacts (such as a wall, column and beam) to support each other or Rachel, its high thick than can be appropriately increased, but should not be greater than those days. Therefore, rammed earth wall should be rammed in the template layer by layer to form its own special texture. Built technical guidance in the new wall green residents atlas, this technique is interpreted as "fail", "flat" and "quantity", "step", "ram" and "fill" six key. Compaction process has strict limits on the thickness of each layer, thickness will affect the integrated intensity of the wall thickness, the thickness of each layer must be controlled within 10 to $15 \mathrm{~cm}$, in the process of the wall will be two-thirds of the undisturbed soil material volume compression to the original volume, so as to achieve the more bearing capacity of rammed earth wall ${ }^{[7]}$.
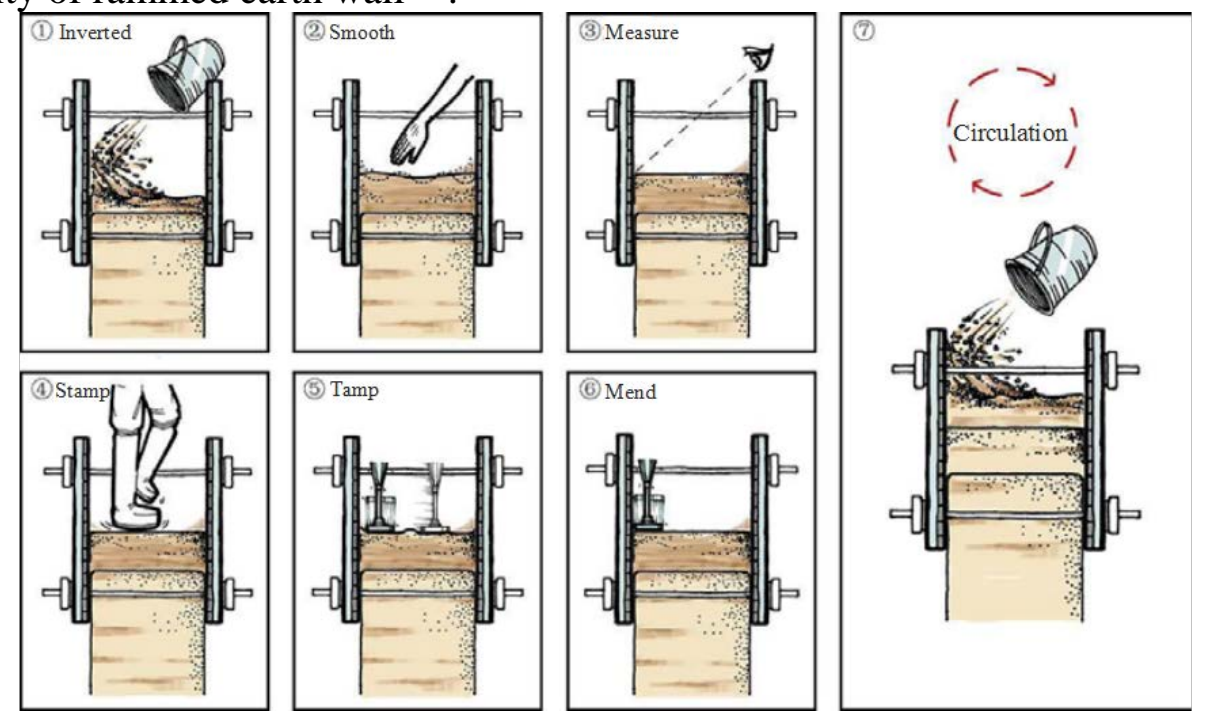

Fig. 5 The ramming process

(image source: "new type rammed earth green residential building guide manual”) 


\section{The Countermeasures and Suggestions for the Development of Rammed Earth Wall in the Construction of New Countryside}

The Yinren county which in Jinhua village of Zhejiang province, is a primitive rammed earth ancient village. Reclusion village of rammed earth wall preservation is very good, in a secluded village rammed earth wall by using new technology, recycling, handling, in situ conservation, function change, reinforcement, process reengineering, to do the old and new contrast to rework.

Furthermore, the local resources are very good, and naturally began to develop tourism. Because many of the local rammed earth wall construction, along with the improvement of living standards and young rural labor force migrant workers, now only one or two people live there, a lot of rammed earth houses spare some parts has been damaged and even withstand the ravages of time. In response to policies, developers actively planning, considering the local culture and cultural history, rammed earth wall of rammed earth building in modern design again, through a series of design innovation. In addition, the secluded village is located in the surrounding area of Hangzhou, which is relatively close to the city. The advantages of long history, rammed earth features and convenient transportation make the village a unique tourist village. In this way, the rammed earth wall remained in the village, and the pattern and environment were preserved. Compared with the secluded village, there are some successful cases of rammed earth inheritance and development in foreign countries for our reference. The Austrian schlins Martin lodge is located in the countryside of western Austria, with beautiful scenery. Martin's home is located at the end of a mountain path that cleverly USES the terrain and has a view of the village. Architect Roger boltzhauser used block operations as the primary means of design and made innovations with Martin rauch's modern ramming technology. Martin rauch to his many years engaged in the construction of rammed earth practice experience applied to the house, the use of pure natural materials, to ensure the structure safety and engineering quality under the premise of made it to the traditional rammed earth technology and innovation ${ }^{[8]}$.

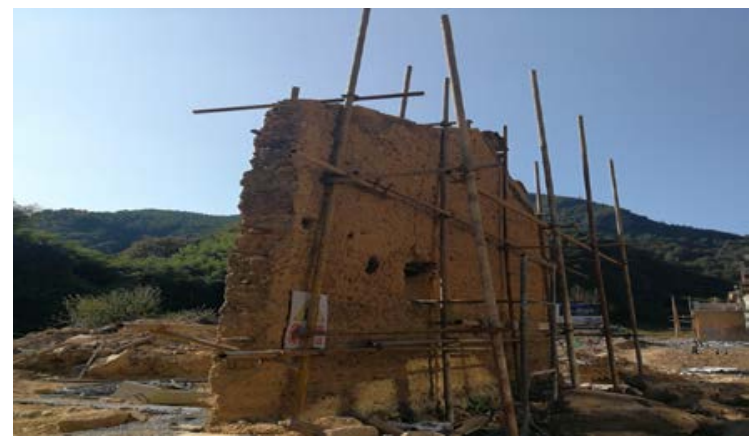

Fig.6 The original oil rammed earth wall of hermit village.

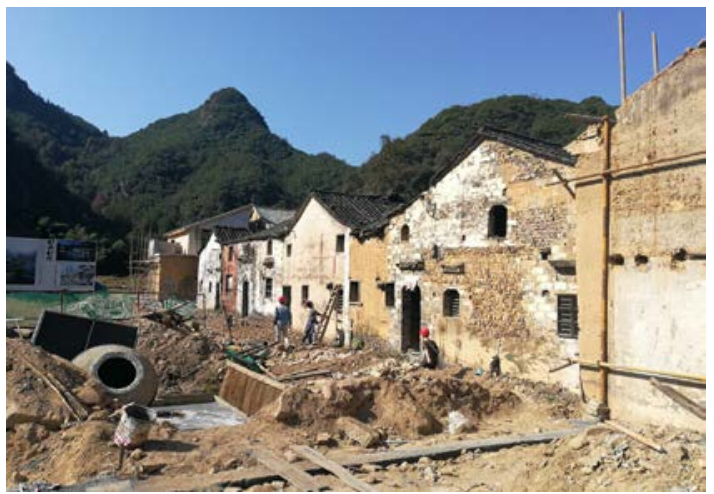

Fig.7 The original rammed earth house village group in the reclusive village. 
In the stage of country development, it is of great importance to broaden the horizons of protecting rammed earth walls. It is very necessary to protect and control the natural geographical environment of rammed earth wall and village. When protecting the traditional rammed earth walls, we should consciously broaden our thinking, from material and cultural heritage to intangible cultural heritage, and comprehensively analyze and understand. In the concrete work, we should also alleviate the construction pressure, control the disorderly spread of the villages, improve the environmental infrastructure of the villages, and promote the progress of the whole countryside.

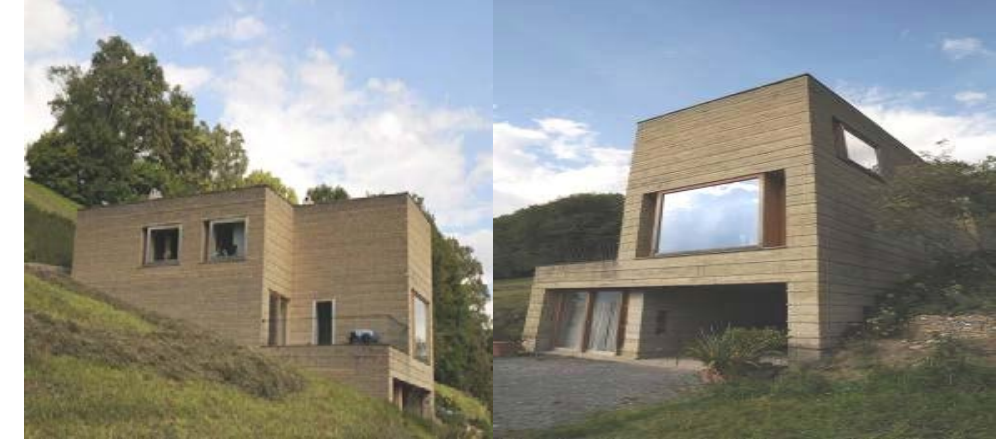

Fig.8 The residence of Martin Rauch.

In today's new situation, rammed earth wall should be in the new rural construction is not the continuation of the original ecological model, because the days are standard has exceeded the traditional, more is we need to meet the needs of modern people rammed earth wall, so the rammed earth wall inheritance is particularly important in the new rural construction. According to the modern requirements, we should make corresponding technological innovation and carry on the inheritance better. To improve the traditional rammed earth wall is to adhere to the path of green development, which is the primary task of improving people's quality of life and the most effective way to save the environment and green sustainable development. Root of rammed earth wall in the countryside, the existence and continuation, which must have its objective existence reasons, rammed earth wall mainly has the following advantages: green environmental protection, construction simple, warm in winter and cool in summer, comfortable, low cost. Rammed earth wall in existing rural existence obvious deformity and humble, demand is relatively far away from the modern live styles, and in people's subjective consciousness, it represents a relatively backward technology level.

\subsection{The process regeneration}

Rammed earth rammed earth wall, the construction of modern technology and the construction of the floor slab of the earth's surface of the limestone and 70 of the aggregate of the cement mixed with the mixture of the soil. Mud plaster, spray before the wall construction of cement pits, make metope keep relative humidity, and choose the sand soil with high sediment concentration, the color of the soil is warm sand soil, which after drying washing unceasingly, this is also the process of soil, after a series of process of mud mixed with $10 \%$ - 20\% of lime, using three kilograms per square meter. If you want to make the effect, you can adjust the mold to achieve the desired effect. By using waterproofing agent to waterproof processing, in order to prevent cracking, sand and gravel, mud and lime to after a certain proportion, clay, mixed with water to form a final shade dry and not exposure.

\subsection{The scientific processing and full utilization}

The traditional rammed earth technology using the modern science and technology to design, 
building technology to architectural interior space, combined with the hot function, the soil made into different shapes. The wall itself divides the internal building space effectively, and controls the thermal performance of the interior space, thus highlighting the livable effect of rammed earth wall. In the large area of indoor and outdoor temperature difference, its effect is remarkable, which makes the living environment more comfortable and is widely used in the green design project of energy conservation and environmental protection. Rammed earth building materials not only work well in architectural design, but also have high aesthetic value. The color of rammed earth layered effect and particle size have different differences, which can be fully utilized in the processing and production. According to the different color, texture and texture of rammed earth wall, it greatly increases the interest of design and maximizes the design requirements of designers.

\subsection{The improvement of matching ratio and construction problem}

According to the modern design thoughts and artistic processing, the number of layers of rammed earth wall, space volume, lighting and improve the study on comfort level, new ideas of rammed earth wall are integrated into the modern aesthetics and the cultural background of the local characteristics of the art processing again. To solve the problem of durability and shock resistance of rammed earth wall, the material ratio and construction method of rammed earth wall need to be improved. Can improve the rammed earth wall of indoor ventilation, Windows and roofs of buildings and design so as to enhance ventilation effect, so conducive to the physical health of the residents, in a relatively successful rammed earth wall buildings, indoor can maintain a relatively stable temperature, summer is cool and comfortable, warm in winter insulation, dependence of air conditioning are greatly reduced, don't consume resources and can adjust indoor temperature, rammed earth wall to do the environmental protection and energy saving. Rammed earth walls are improved in lighting, heating and lighting, reducing resource consumption and environmental damage in new rural construction.

Nowadays, the advantages of rammed earth wall in ecology, environmental protection and low carbon have been recognized by more and more designers and adopted in architectural design. In view of the traditional rammed earth wall defect of local-style dwelling houses building and development and the plight of the inheritance of nearly ten years, we the original group of traditional rammed earth wall construction process of excavation, improvement and innovation, a series of in-depth research, experiment research and demonstration construction, a series of results, which has attracted great concern of the industry and the public, for the traditional architectural culture heritage and the sustainable development of rural construction, has played a certain demonstration and promotion effect.

\section{Conclusion}

The rammed earth wall, following the witness of the five thousand years of history and civilization of the Chinese nation, is the historical treasure left by the old ancestors. In the beautiful countryside construction vigorously promote sustainable development, today, by means of rammed earth wall in the widespread investigation and study of new rural construction, use modern technology to improve, to make a further play the advantage of rammed earth wall, thus a new vigor and vitality. Found the rammed earth wall in the current problems in the construction of new countryside, to use modern technology to transform and protection, this is the inheritance and development of rammed earth wall, which find a new breakthrough for the new rural construction. At the same time, the inheritance and development of rammed earth wall can reduce rural consumption of building materials, and to improve the rural living environment, improve the quality of rural life, to solve the problem of the people's livelihood, promote the new rural construction, the 
construction of a conservation-minded society, building a harmonious socialist society, focus on building beautiful new China has played a vital role.

\section{References}

[1] Mu Jun. A guide to the construction of new rammed earth green dwellings. China construction industry press, 2014.8 .

[2] Yuan Hao. An analysis on the application of modern rammed earth construction technology in architectural design [J]. Beijing university of technology, 2017 (05): 54.

[3] Martin Lauch, Shang Jin. Lauch, schlins. Austria [J]. World architecture. July, 2011:54.

[4] Hao Jun. Construction technology of new rammed earth wall [J]. Construction workers, 2017 (07): 16-19.

[5] Xu Ying. Analysis of basic mechanical properties and structural performance of new rammed earth building materials [D]. Xi 'an: xi 'an university of architecture and technology, 2016.

[6] Huang Yan. Case study of modern rammed earth construction [D]. Xi 'an university of architecture and technology,2017.

[7] Lin Ting. Clay_ concrete _ soil materials and rammed earth construction [J]. Construction technology, 2013 (03): 0238-0242.

[8] Xu Liping. Application of rammed earth wall in new local ecological architecture [J]. Sichuan architectural science research, 2007 (06): 0212-0217. 